\title{
Suchitoto, un patrimonio que se transforma: ¿para quién? ¿Para qué? ¿Y sus herederos? Hacia una reflexión del valor humano del patrimonio edificado.
}

\author{
Ramón D. Rivas \\ Dirección de Cultura-Museo \\ Universitario de Antropología. \\ Universidad Tecnológica de El Salvador \\ ramon.rivas@utec.edu.sv
}

DOI: http://dx.doi.org/10.5377/koot.v0i8.5874

URI: http://hdl.handle.net/11298/388

\section{Resumen}

La ciudad de Suchitoto, ubicado en el departamento de Cuscatlán, es un lugar rico en historia, calzado por un patrimonio que fue heredado desde los primeros años de la república, con un impresiónate legado histórico, tanto en tradiciones y arquitectura, la cual ha resistido el paso de los tiempos, permitiendo a sus actuales dueños, ser disfrutado por visitantes nacionales e internacionales.

Es una herencia que identifica y da pertenencia a todos sus pobladores. Es parte de la identidad de los salvadoreños. Pero ¿qué sucede cuando por situaciones de carácter endógeno, los que han heredado y vivido en el lugar, tienen que salir y dejar sus raíces? ¿Qué sucede cuando el patrimonio es intervenido por el comercio y los factores de desarrollo? ¿Qué pasa con aquellos que dejaron su patrimonio cultural, tangible e intangible, para incorporarse a otros nichos sociales fuera de sus fronteras? ¿Cómo se transforma esa cultura?

Esta es una realidad que la vive Suchitoto y la están viviendo millones de personas y sociedades en el mundo, desarrollados o no, que debemos analizarla y reflexionarla antropológicamente, a fin de encontrar un significante y un significado que sirva de ruta para impulsar mejores políticas públicas que beneficien la conservación y la puesta en valor del patrimonio cultural de los pueblos; ya que el patrimonio es identidad, y por ende, un importante referente cultural de su gente.

Sin duda alguna, patrimonios valiosos como Suchitoto se están transformado sin el verdadero valor humano con la cual fue construido por sus ancestros; y sus más recientes pobladores están emigrando a otras sociedades del mundo, caracterizado por el consumismo, dejando su riqueza cultural en manos de extraños que buscan transformarla sin tomar en cuenta la historia, la tradición y 
el componente humano y arquitectónico que sirvieron de base para erigir este valioso patrimonio cultural.

Sabemos que la cultura, el patrimonio y la identidad se transforman, proceso normal en toda sociedad, pero no es justo que se produzca una transformación inducida por instancias que se posicionaron del lugar, sin que estos lo conozcan y lo cambien sin saber cuál era el verdadero valor histórico que tuvo en su época.

Palabras claves: Paisaje cultural, registro etnográfico, memoria, transmisión intergeneracional, comercio, migraciones.

\begin{abstract}
The city of Suchitoto, located in the department of Cuscatlán, is a place rich in history. It is embedded by a cultural heritage that was inherited from the early years of the republic, with an impressive historical legacy both in traditions and architecture which has survived until our present, allowing its current owners enjoy national and international tourists and visitors.
\end{abstract}

Such heritage projects identity and a sense of belonging to all its inhabitants. In fact, it is an essential component of the identity of the Salvadorans. However, what happens when due to situations of endogenous nature, those who have inherited and lived in the place have to leave and leave their roots? When is cultural heritage affected by trade and economic and social development factors? What about those who left their cultural heritage, tangible and intangible, in order to integrate other social niches outside their borders? How is this culture transformed?

This is a reality that Suchitoto is going through and millions of people are witnessing in cities in the world in both developed and underdeveloped countries. We must analyze and reflect this aspect from an anthropological stand point by finding a signifier and a meaning that serve as a path to promote better public policies that value the conservation and enhancement of the cultural heritage of the peoples since cultural heritage is identity, and therefore, an important cultural reference of its people.

Undoubtedly, valuable estates like Suchitoto are being transformed without the true human value with which was built by their ancestors. Moreover. Even its most recent inhabitants are emigrating to other cities of the world, as a sign of the trends of current consumption, leaving their cultural wealth in the hands of strangers who seek to alter it without taking into account the history, tradition 
and the human and architectural component that served as a base to set up this valuable cultural heritage.

We are aware that culture, heritage and identity are transformed as a normal process in any society, but it is not reasonable that a transformation is induced by new located players who are unaware of the rich historical and cultural values Suchitoto had in its memorable times.

Keywords: Cultural landscape, ethnographic record, memory, intergenerational transmission, trade, migration.

Antropológicamente Suchitoto aún conserva una riqueza cultural heredada de sus primeros habitantes: los pipiles. A tan solo 10 kilómetros al sur de Suchitoto se encuentra Ciudad Vieja, un sitio considerado de mucho valor histórico porque se ha comprobado que fue unos de los lugares colonizado por los españoles, para establecer la primera Villa de San Salvador, por el entonces Diego de Alvarado (1525).

Según los estudios hechos por William R. Fowler, en esta región se encontraron cuatro estructuras que pertenecieron a la antigua villa de San Salvador de 1528. El estudio hecho por Fowler confirma, tal cual lo señaló en el prólogo del libro, "que es un sitio arqueológico de singular importancia para encontrar las raíces de nuestra salvadoreñidad, un sitio en donde muy bien se pueden conjugar estudios antropológicos, arqueológicos e históricos desde antes de la Conquista y los años que le siguieron".

La ciudad cuenta actualmente con más de 26 mil habitantes, y el mayor rubro de ingresos es el turismo. Su nombre es de origen náhuatl y se pronunciaba en el pasado como "Xotchil totol", que traducido al castellano significaba "pájaroflor".

Hace 154 años se le otorgó el título de ciudad, para ser exacto, el 15 de julio de 1858. Su atractivo natural en la actualidad es el lago artificial de Suchitlán; bautizado con ese nombre por el insigne cineasta Alejandro Cotto, quien unió las silabas "Suchi” de Suchitoto y "Tlán" de Cuscatlán.

En este paradisíaco lugar se encuentra el embalse del Cerrón Grande, construido en 1972 por el entonces presidente de la república, el coronel Arturo Armando Molina para generar energía eléctrica para una buena parte de nuestro país.

El 15 de mayo de 1997, la Asamblea Legislativa declaró a Suchitoto como "Conjunto Histórico de interés cultural", principalmente por tener 46 inmuebles de gran valor cultural. 
Entre su riqueza arqueológica y patrimonial se pueden mencionar: Ciudad Vieja, la cual mencionamos al principio de nuestra ponencia; el Casco de la Hacienda La Bermuda, construida hacia el año 1600; el Casco de la Hacienda Colima, con una antigüedad de más de 100 años y con el potencial de ser investigado por su valor histórico; la Hacienda Milingo, vinculada en su momento histórico con los cultivos tradicionales de la zona (añil); las Iglesias de Aguacayo, Ichanquezo y Santa Lucía, construidas en la época colonial; la casa del cineasta Alejandro Cotto, convertida hoy en museo con valiosos objetos de valor tanto cultural como histórico, algunos de hasta 400 años de antigüedad. Su colección comprende pinturas, fotografías, muebles, hemeroteca y filmoteca; diversas viviendas particulares, espacios públicos, detalles arquitectónicos de interés singular.

El Museo Comunitario "La memoria vive", el cual fue inaugurado en septiembre de 2010. Este museo exhibe cinco áreas para conocer la historia y las tradiciones de Suchitoto y de las comunidades que lo habitan; el Museo de la moneda, una obra inaugurada en junio de 2011 para establecer cinco salas de exposiciones que son visitadas por turistas de diversos sectores del mundo. En las salas se muestran imágenes de carácter religioso y otra está dedicada exclusivamente a billetes y monedas de El Salvador; las otras dos a diferentes monedas del resto del mundo, entre las que está un tetradracma, que es la más antigua del museo. Similar a este museo está la Casa de la Abuela, un espacio donde el arte y la venta de artesanía se posicionan. Podría seguir enumerando otros lugares, pero ante la falta de tiempo, me quedaré hasta este lugar.

Ahora bien, aunque Suchitoto cuenta con un Plan de Desarrollo Turístico, con leyes, ordenanzas y regulaciones municipales que amparan su patrimonio más representativo y que le facultan para su conservación, existe infraestructura instalada que está siendo modificado por los nuevos propietarios que están llegado a la zona para instalar sus empresas o comercio que de una u otra manera afecta el patrimonio cultural de la zona.

Es un hecho que la tasa de crecimiento poblacional es elevada, según los últimos estudios de población hechos por la Dirección General de Estadística y Censos del Ministerio de Economía. Hay necesidad de abrir más fuentes de trabajo, más viviendas y más comercio para atender la demanda de la población que crece. Solo en 2007, las tasas de crecimiento poblacional de Suchitoto se dan más en el área rural del municipio. El 8.8\% de la población recibe remesas familiares del exterior, dato reportado por la Fundación Nacional para el Desarrollo, Funde, en el 2007.

Por ello, y ante la necesidad de emplear a las nuevas generaciones en actividades productivas de la zona, más de 400 empresas de diferentes sectores productivos 
y de servicios están registradas en la Alcaldía Municipal de Suchitoto para poder operar en la zona. Sorprendente ¿verdad?

\section{La pregunta ante todo lo expuesto es: ¿Para quién se transforma Suchitoto?}

Con los pocos datos que he mostrado anteriormente, podemos interpretar que la necesidad de desarrollo económico de Suchitoto impulsa a las autoridades locales a ceder espacios que de una u otra forma atentan o afectan el patrimonio edificado de los pueblos. Debo aclarar que no estoy en contra del desarrollo de los pueblos; pero si de todo aquello que de una u otra forma atenta contra los valores y principios culturales que dieron forma a nuestra identidad como personas, como ciudadanos y como miembros de una comunidad.

Esta realidad planteada no es un fenómeno que solo se vive en El Salvador. Estoy más que seguro que está ocurriendo en diferentes partes del mundo. Por ello mi interés en reflexionar sobre la problemática, ya que el patrimonio cultural de nuestros pueblos cada vez se ve amenazado, no por el desarrollo turístico; más bien, por personas que llegan a estos inmuebles, desconocedores de las tradiciones, costumbres y valor histórico que ha conservado por décadas.

Es lógico pensar que el patrimonio edificado se ve amenazado por privados, ya sea individuales y colectivos, que buscan modernizar la infraestructura sin ponerse a pensar del daño que causan a la cultura y a la misma identidad de los pueblos.

Si partimos del concepto que patrimonio cultural es todo aquello que nuestros antepasados nos legaron, convirtiéndose en evidencia que identifica y distingue a la cultura propia de la ajena, dándole sentido y partencia a los diversos componentes de nuestro acervo cultural; debemos entonces poner una luz de emergencia que llame la atención a la academia, hacedores de políticas públicas y gobernantes ante el deterioro que están sufriendo nuestros lugares más emblemáticos de nuestra cultura.

Es triste mirar cómo viviendas con gran valor histórico de Suchitoto son ahora ocupadas por personas que muy poco o nada saben del aporte identitario que brindan a la comunidad, al pueblo o país mismo. No importa si los habitantes de ese inmueble sean nietos o bisnietos de los propietarios originales del lugar o la zona. El valor cultural se pierde cada día por la misma transculturización o globalización de la cual habla el filósofo Héctor Samour al señalar que el consumismo es tan poderoso que ha permeado hasta en la cultura misma de los seres humanos. 
Aquí estoy planteando dos dimensiones del problema: la pérdida de valor al patrimonio cultural con la llegada de nuevas formas de consumo y relaciones; así como el daño que sufre nuestra herencia o creación con la llegada de propietarios foráneos a los lugares que han dado forma a nuestra identidad.

En el primero de los casos, tomo como ejemplo Suchitoto, un pueblo que su patrimonio cultural pierde sentido para las nuevas generaciones, controladas por una cultura globalizada, en donde la tecnología ha desplazado hasta las formas de relacionarnos y comunicarnos, no logran valorizar la riqueza cultural que se les ha heredado y que, con los años transcurridos, su valor se ha incrementado para beneficio propio y de todo un país. Pero este valor no se le está otorgando por causa de las nuevas formas de ver nuestro mundo por medio de las tecnologías.

De ahí que no resulta extraño ver cómo los actuales propietarios de valiosos inmuebles de gran valor histórico que hay en Suchitoto, entregan a foráneos su patrimonio, muchas veces para migrar a otros países con el dinero conseguido, o involucrarse en actividades comerciales a costa de su identidad y su cultura.

No es posible concebir que en nombre de la modernidad y por el deseo de un desarrollo económico de una microrregión, el patrimonio cultural sea el primero en verse afectado, mercadeado o tranzado para lograr objetivos más que colectivos, son de carácter privado. Y, aunque fuesen colectivos, no se puede tirar al olvido, una herencia forjada por hombres y mujeres que construyeron una identidad basada en valores y costumbres que de una u otra formas los hicieron grandes.

Si dejamos que esto siga creciendo, entonces estaremos enterrando nuestro pasado como referente de experiencias y argumentos que son importantes para saber quiénes somos, de dónde venimos y para dónde vamos. Además, se pondría aún más en peligro el sentido de identidad, de pertenencia y una razón más para vivir y trabajar por nuestra familia, nuestra localidad, nuestra región, nuestra Nación. Pueblos como El Salvador se debaten en un conflicto social que no encuentra sentido. Esa es una causa de la falta de identidad y de no saber quiénes somos los salvadoreños.

La segunda dimensión, relacionada con la llegada de personas extrañas o desconocedoras del patrimonio de Suchitoto, la explicaré partiendo de una reflexión hecha por Alain Touraine, en su libro "El fin de las sociedades", en el cual explica: "los antiguos mundos colonizados y conquistados tienden a rechazar la modernidad con su unidad, porque prefieren la idea de una pluralidad de los modos de modernización, debido, en parte, a su historia y al recuerdo de supremacía, así como, en parte, a su fidelidad a un universalismo cuya expresión política es la democracia”. 
No cabe duda que la modernidad es importante en nuestros países. Pero, ¿debe la modernidad desplazar el patrimonio edificado de nuestros pueblos? Mi respuesta es un rotundo no. Creo que modernidad y antigüedad deben subsistir ambas, entremezclarse, fomentarse una con otra y sobre todo, promoverse turísticamente una a la otra sin romper con su particularidad.

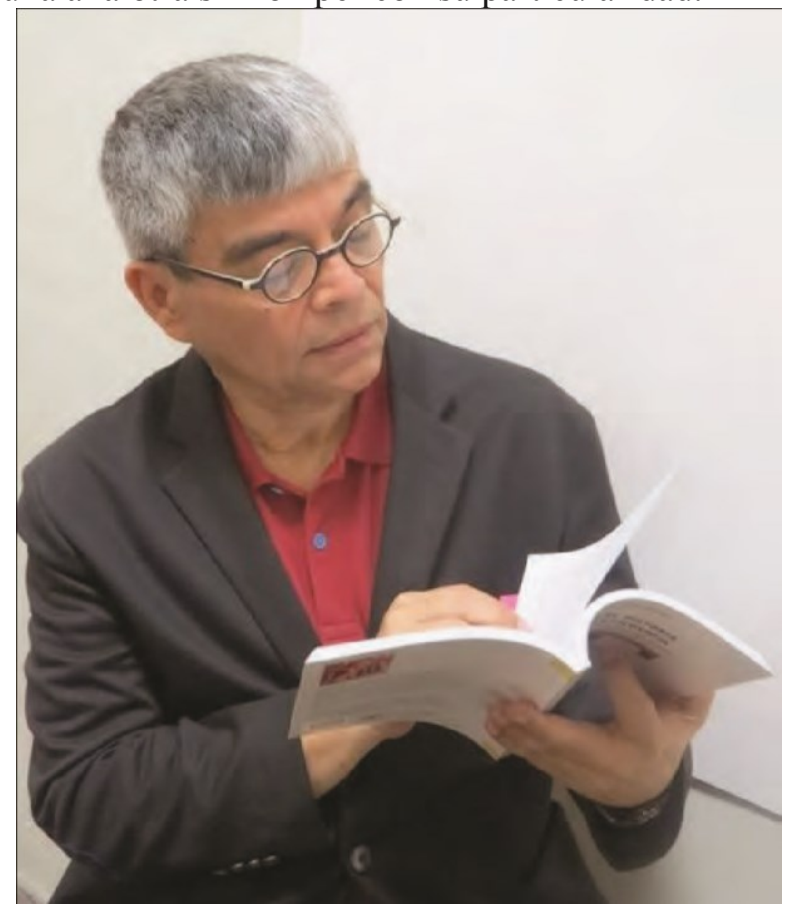

Ramón D. Rivas

Pero esto no ocurre en la actualidad. Una quiere sustituir a la otra, y si ambas tienen ese derecho a la existencia, entonces, sobre la base de una democracia, debemos respetar y permitir que pasado y presente patrimonial caminen juntos para beneficio de toda la humanidad.

Hay países que ya han caminado sobre esta idea, fomentando el turismo cultural sin dañar el patrimonio de los pueblos. La base de esta buena relación ha sido que los tomadores de decisiones se han acercado al patrimonio para observarlo y comprenderlo como un producto de la sociedad misma, en su estado permanente de cambio. No somos lo que hoy pensamos ser, más bien, somos lo que otros quisieron que fuésemos. Esto es un proceso de cambio mediado por la cultura, responsable de moldear a las nuevas generaciones que habitan un sector de nuestro planeta. Por ello, considero que la modernidad no debe desplazar nada de nuestro patrimonio, debe aprender a convivir con el pasado. 
Entonces, ¿a quién corresponde proteger nuestro patrimonio cultural? ¿El gobierno? ¿El heredero? o ¿los antropólogos? La respuesta creo que está en todos, pero al asignarse la responsabilidad a la generalidad, es cuando nadie es responsable de nada. De ahí que debemos impulsar desde estos foros de reflexión, un acuerdo que nos lleve a ser más proactivos en estos temas para liderar políticas de protección al patrimonio cultural de nuestros pueblos, ya que la modernidad, el turismo, la indiferencia de sus herederos y hasta la poca visión del estado en estos temas, nos podría llevar a contemplar un desastre cultural en nuestros días.

Para finalizar, quiero enfatizar que la ciudad de Suchitoto, ubicado en el departamento de Cuscatlán, es un lugar rico en historia, calzado por un patrimonio que fue heredado desde los primeros años de la república, con un impresiónate legado histórico, tanto en tradiciones y arquitectura, la cual ha resistido el paso de los tiempos, permitiendo a sus actuales dueños, ser disfrutado por visitantes nacionales e internacionales.

Es una herencia que identifica y da pertenencia a todos sus pobladores. Es parte de la identidad de los salvadoreños. Pero la migración de sus herederos pone en peligro ese patrimonio lleno de riqueza histórica e identitaria con la llegada de nuevos inquilinos que están atrapados por la modernidad y las nuevas tecnologías.

Por eso cuando uno se hace la pregunta ¿Qué sucede cuando el patrimonio es intervenido por el comercio y los factores de desarrollo? ¿Qué pasa con aquellos que dejaron su patrimonio cultural, tangible e intangible, para incorporarse a otros nichos sociales fuera de sus fronteras? ¿Cómo se transforma esa cultura?, se hace necesario reaccionar de forma inmediata para proponer alternativas de solución o medidas que ayuden a frenar un eventual deterioro del patrimonio edificado e intangible de nuestros pueblos.

Sin duda alguna, patrimonios valiosos como Suchitoto se están transformado sin el verdadero valor humano con la cual fueron construidos por sus ancestros; y sus más recientes pobladores dejan una riqueza cultural que es poco valorada por los nuevos inquilinos.

Recordemos que la cultura nos da identidad, y si la identidad se destruye, tendremos personas que no encontrarán sentido de pertenencia para su tierra, sus semejantes y su vida misma. 


\section{Panorámicas de tiendas artesanales, restaurantes, hoteles y otros espacios de atracción turística en la ciudad}

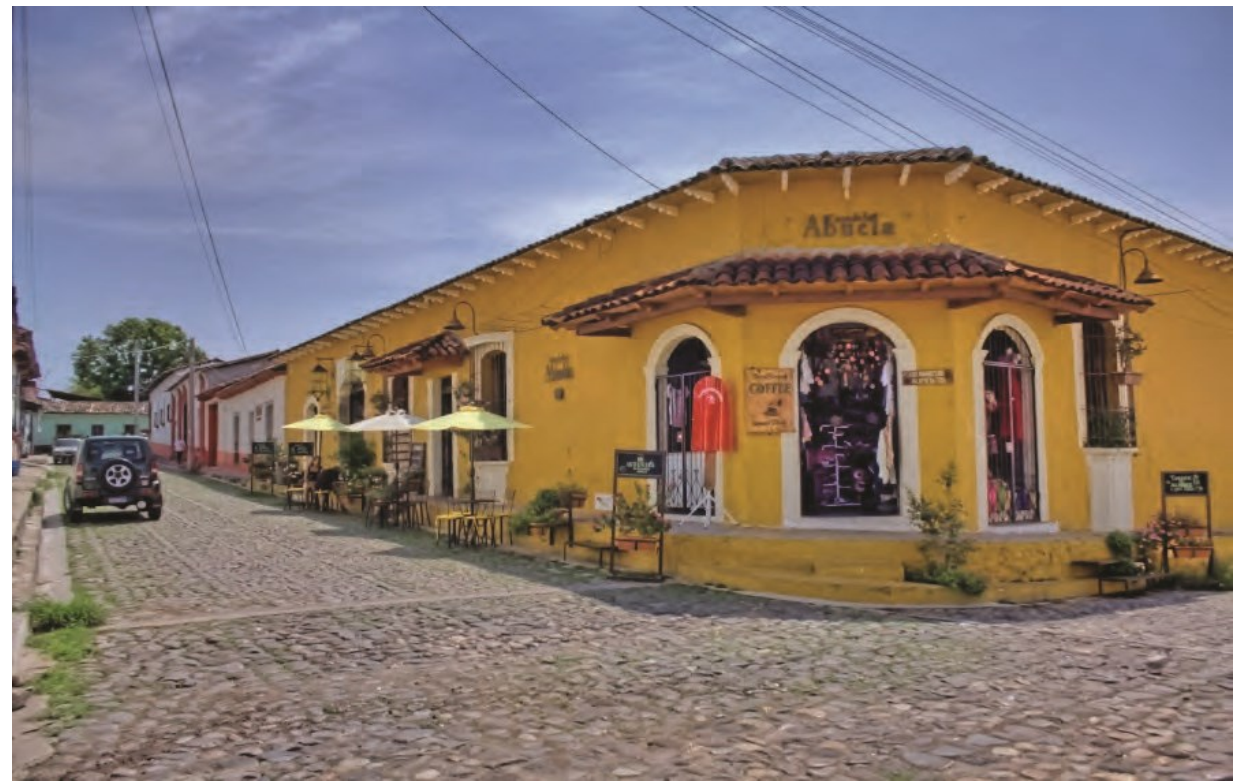

Fotografía: Hugo Henríquez (Utec)

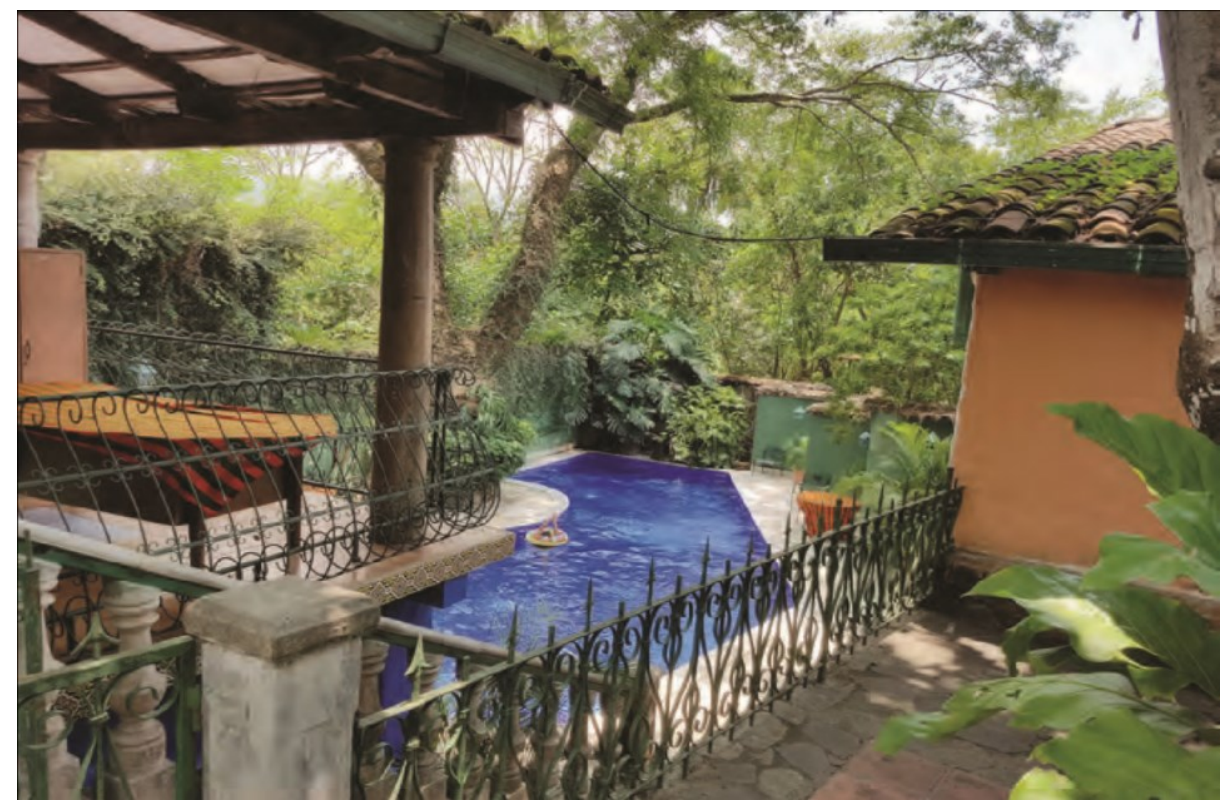

Fotografia: Ramón D. Rivas (Utec)

(C) Universidad Tecnológica de El Salvador

REVISTA DE MUSEOLOGÍA KÓOT, 2017 AÑO 7, n. ${ }^{\circ}$ 8, ISSN 2078-0664, ISSNE 2378-0664 


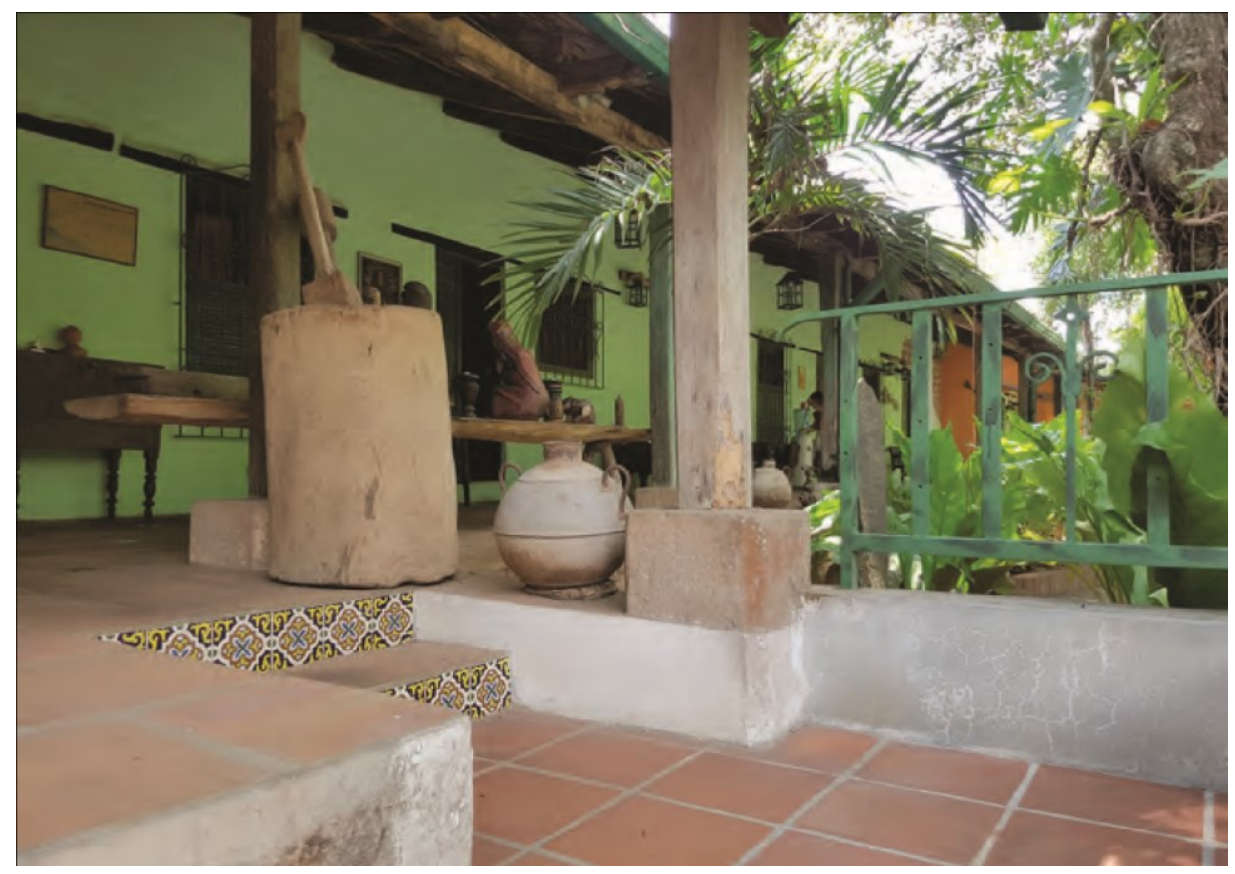

Fotografia: Ramón D. Rivas (Utec)

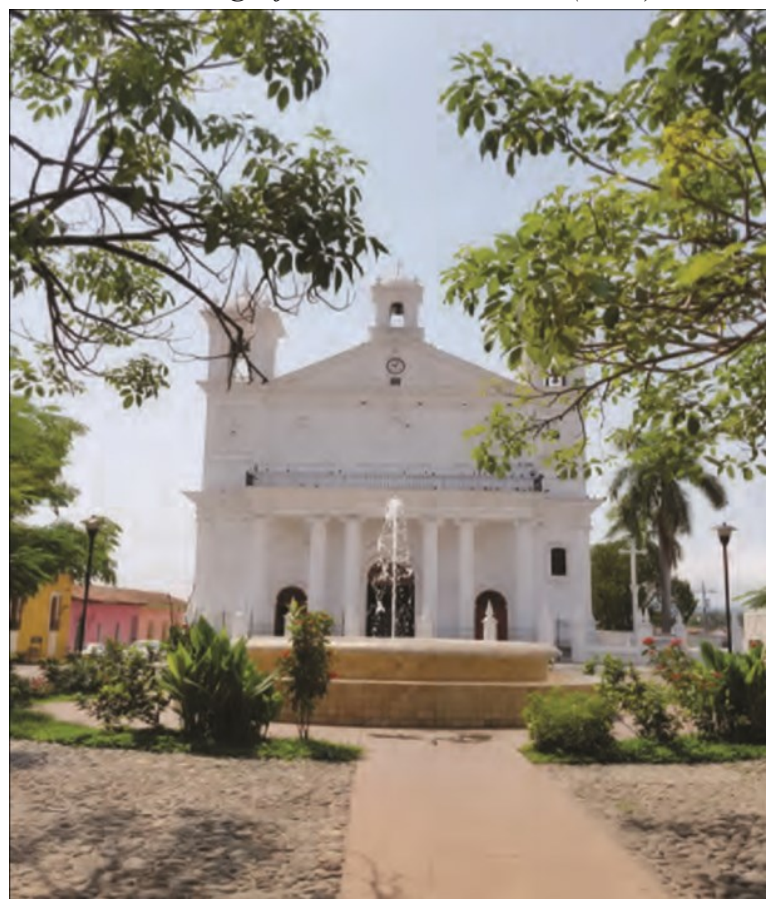

Fotografia: Ramón D. Rivas (Utec)

(CUniversidad Tecnológica de El Salvador 
Rivas, Ramón D. Suchitoto, un patrimonio que se transforma: ¿para quién? ¿Para qué? ¿Y sus herederos? Hacia una reflexión del valor humano del patrimonio edificado. Págs. 187-201.

DOI: http://dx.doi.org/10.5377/koot.v0i8.5874

URI: http://hdl.handle.net/11298/388

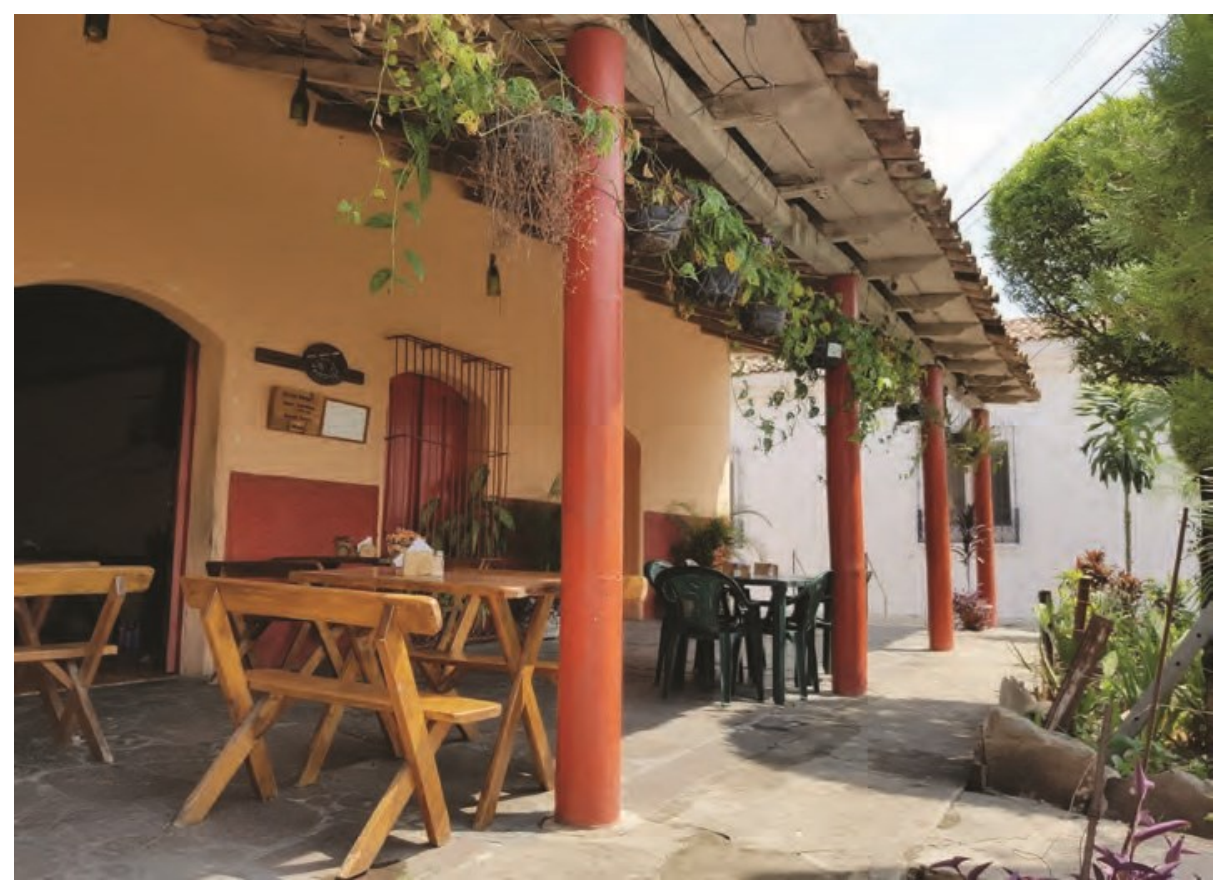

Fotografia: Ramón D. Rivas (Utec)

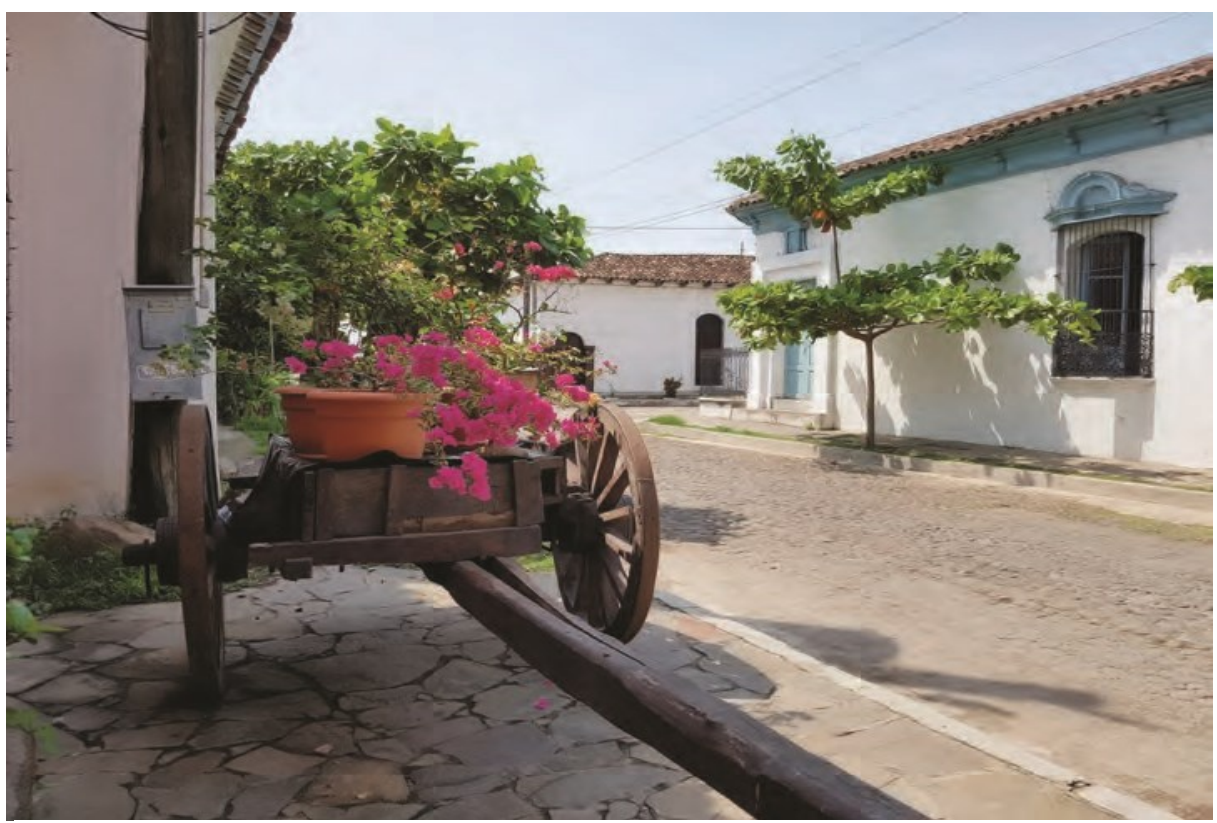

Fotografia: Ramón D. Rivas (Utec)

CUniversidad Tecnológica de El Salvador

REVISTA DE MUSEOLOGÍA KÓOT, 2017 AÑO 7, n. ํ 8, ISSN 2078-0664, ISSNE 2378-0664 
Rivas, Ramón D. Suchitoto, un patrimonio que se transforma: ¿para quién? ¿Para qué? ¿Y sus herederos? Hacia una reflexión del valor humano del patrimonio edificado. Págs. 187-201. DOI: http://dx.doi.org/10.5377/koot.v0i8.5874 URI: http://hdl.handle.net/11298/388

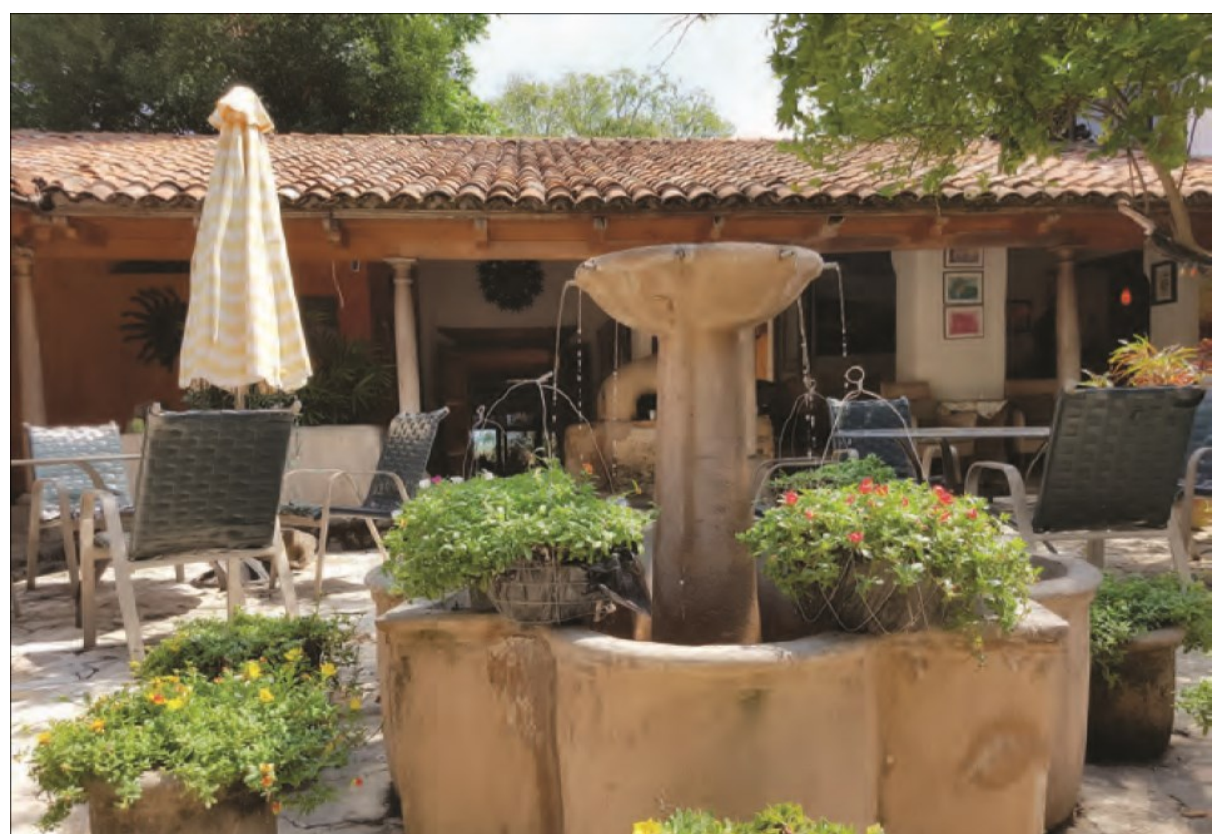

Fotografia: Ramón D. Rivas (Utec)

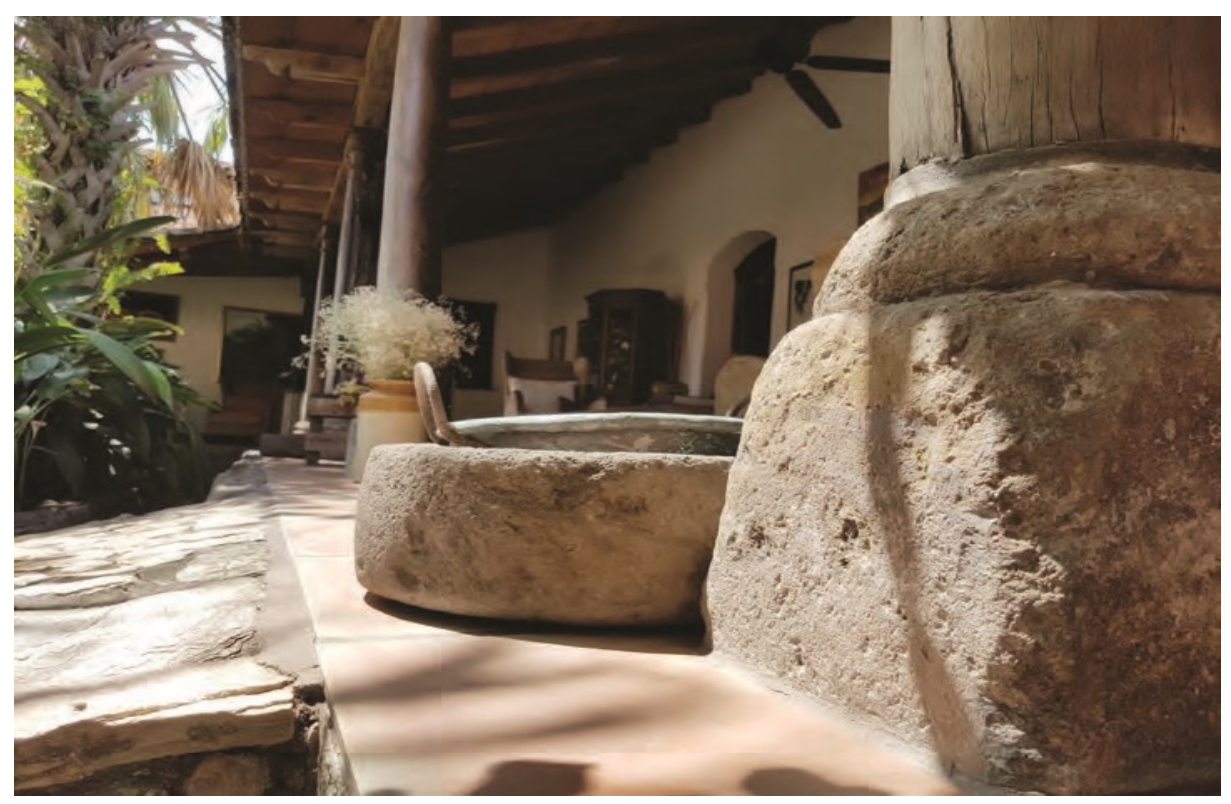

Fotografia: Ramón D. Rivas (Utec)

(C) Universidad Tecnológica de El Salvador 
Rivas, Ramón D. Suchitoto, un patrimonio que se transforma: ¿para quién? ¿Para qué? ¿Y sus herederos? Hacia una reflexión del valor humano del patrimonio edificado. Págs. 187-201. DOI: http://dx.doi.org/10.5377/koot.v0i8.5874 URI: http://hdl.handle.net/11298/388

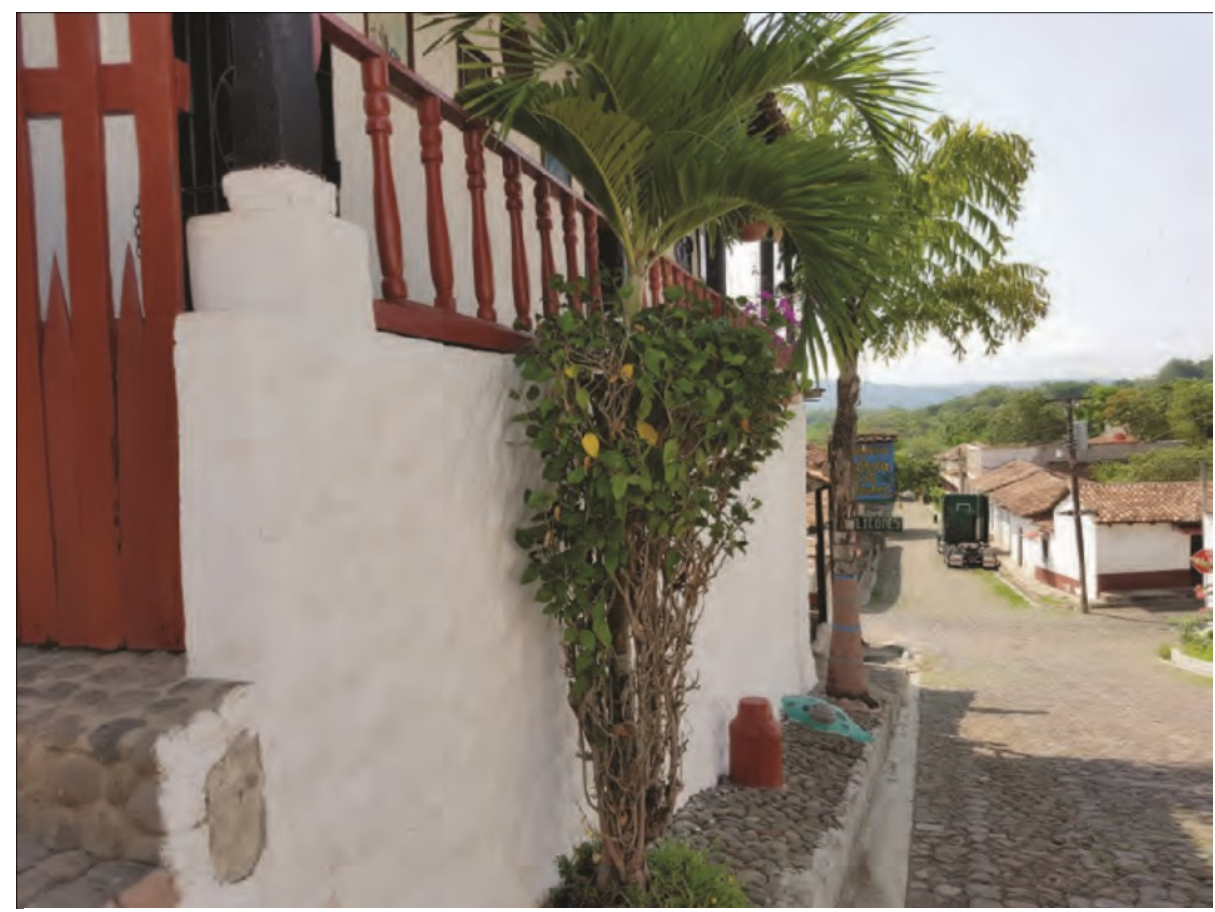

Fotografia: Ramón D. Rivas (Utec)

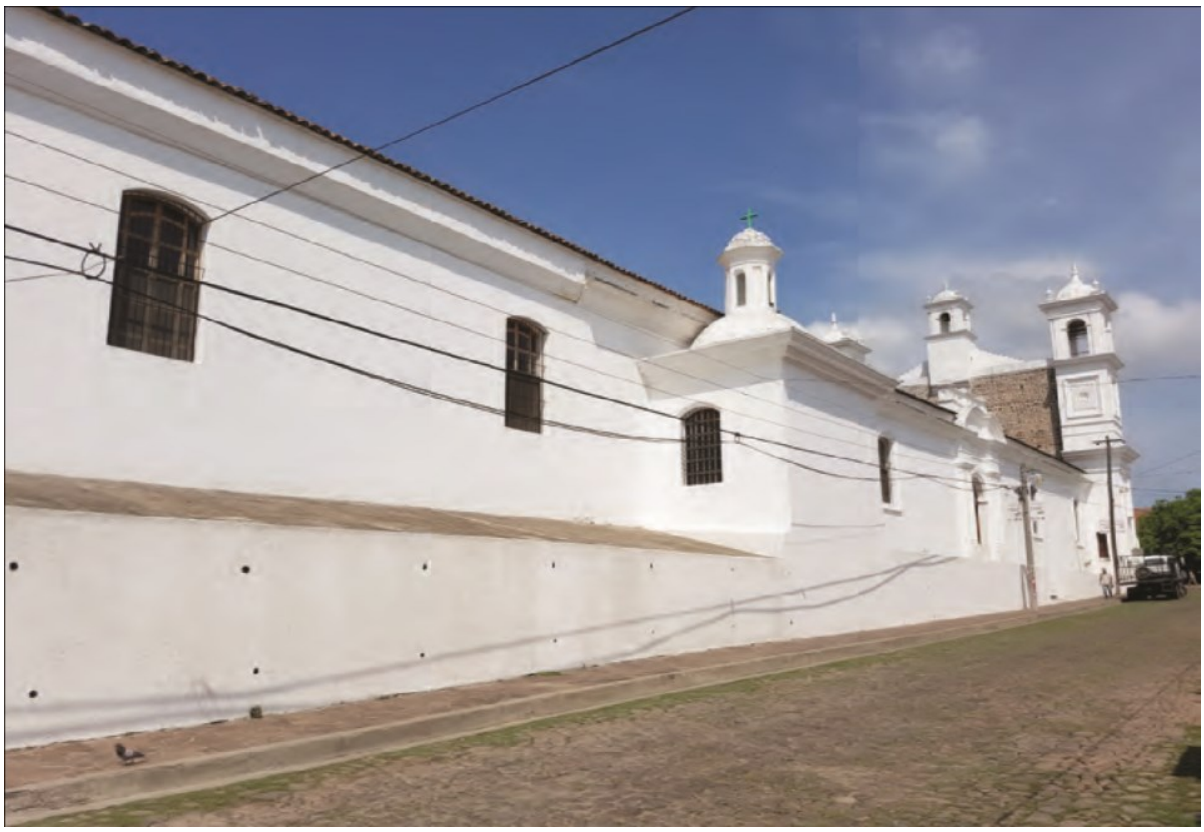

(C) Universidad Tecnológica de El Salvador

REVISTA DE MUSEOLOGÍA KÓOT, 2017 AÑO 7, n. ํ 8, ISSN 2078-0664, ISSNE 2378-0664 


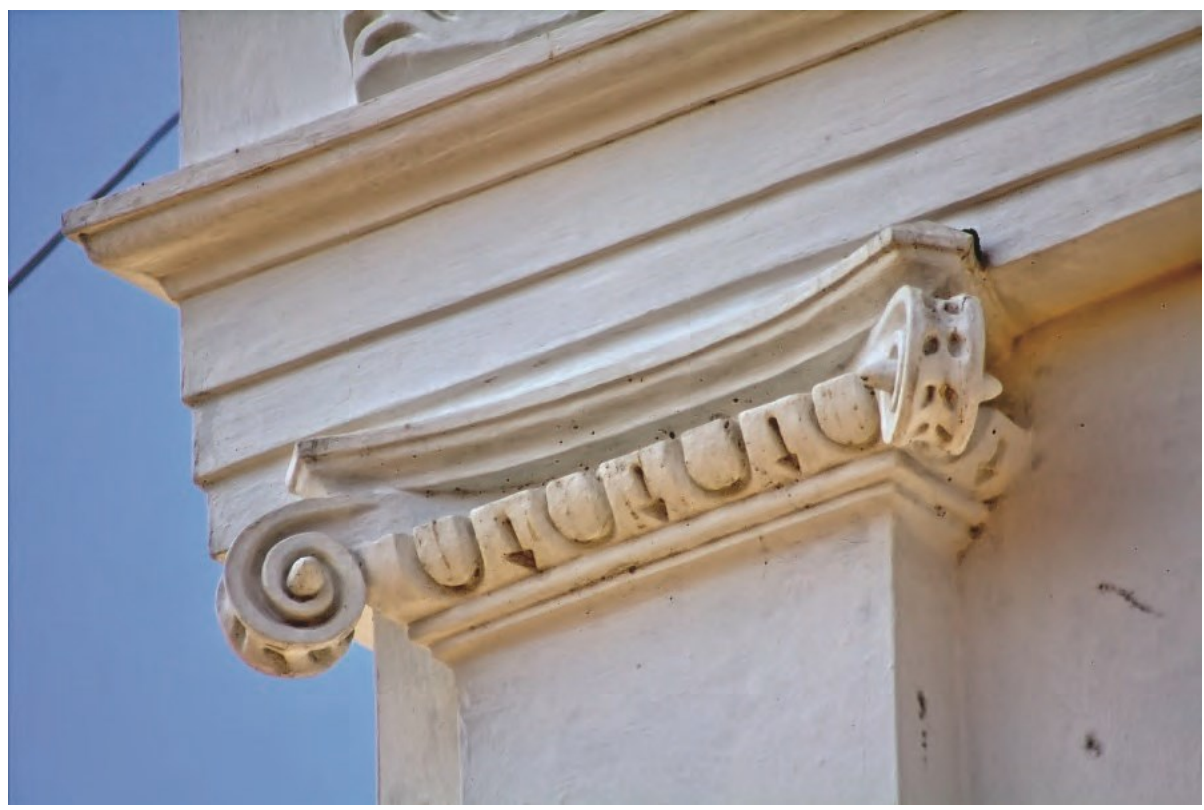

Fotografía: Hugo Henríquez (Utec)

\section{Referentes bibliográficos}

Amescua, F. (comp.), El patrimonio cultural a la venta. Ciudad de México: Ediciones Taller Abierto. 2000.

Barberena, I. Santiago. Monografías departamentales. Dirección de Publicaciones e Impresos. Concultura. San Salvador, El Salvador. 1998.

Bid. Una obra en marcha: el Banco Interamericano de Desarrollo y la protección del patrimonio cultural. Washington D.C.: BID. 2001.

Burgos, Hugo de. Suchitoto. Dirección de Publicaciones e Impresos. Concultura. San Salvador, El Salvador. 1999.

De La Calle, M. (2006), La ciudad histórica como destino turístico. Barcelona: Ariel. 2006.

Medina, D. Arquitectura y turismo, percepción, representación y lugar. Barcelona: Gustavo Gili. 2006.

Noelle, L. (comp.), Patrimonio y turismo. México: IIE-UNAM.1998.

Pardo, C. Turismo y patrimonio industrial. Madrid: Síntesis.2008. 
Rivas. Ramón D. y otros. Deseo Local y Patrimonio Histórico en Sichitoto. Facultad de Arte y Cultura. Universidad Tecnologica de El Salvador. N. 3 Colección Antropología. Tecnoimpreso. S.A de C.V. San Salvador. El Salvador. Maryo. 2005.

Rojas, E. Old Cities, New Assets, Preserving Latin America's Urban Heritage. Washington D. C.: Inter-American Development Bank. 2000.

Fowler JL. E. William y Roberto Gallardo. Investigaciones arqueológicas en Ciudad Vieja. Concultura. Dirección de Publicaciones e Impresos. San Salvador, El Salvador. 2003.

González-Varas, I. Conservación de bienes culturales. Teoría, historia, principios y normas. Madrid: Cátedra (Manuales de Arte). 2000.

Herzog, L, Return to the Center: Culture, Public Space and City Building in a global Era. Austin: University of Texas Press.2006.

Instituto de Mejoramiento Integral de Poblados. Primer foro nacional para el mejoramiento integral de poblados y ciudades. San Cristóbal de las Casas: Gobierno del Estado de Chiapas-Lindero Ediciones. 2003.

Melé, P. La producción del patrimonio urbano. México: Centro de Investigaciones y Estudios Superiores en Antropología Social (CIESAS). 2005.

Mesías, R. y Suárez, A. (2001), Los centros vivos. Alternativas de hábitat en los centros antiguos de las ciudades de América Latina. La Habana-México: Programa Iberoamericano de Ciencia y Tecnología para el Desarrollo (CYTED). 2001. 


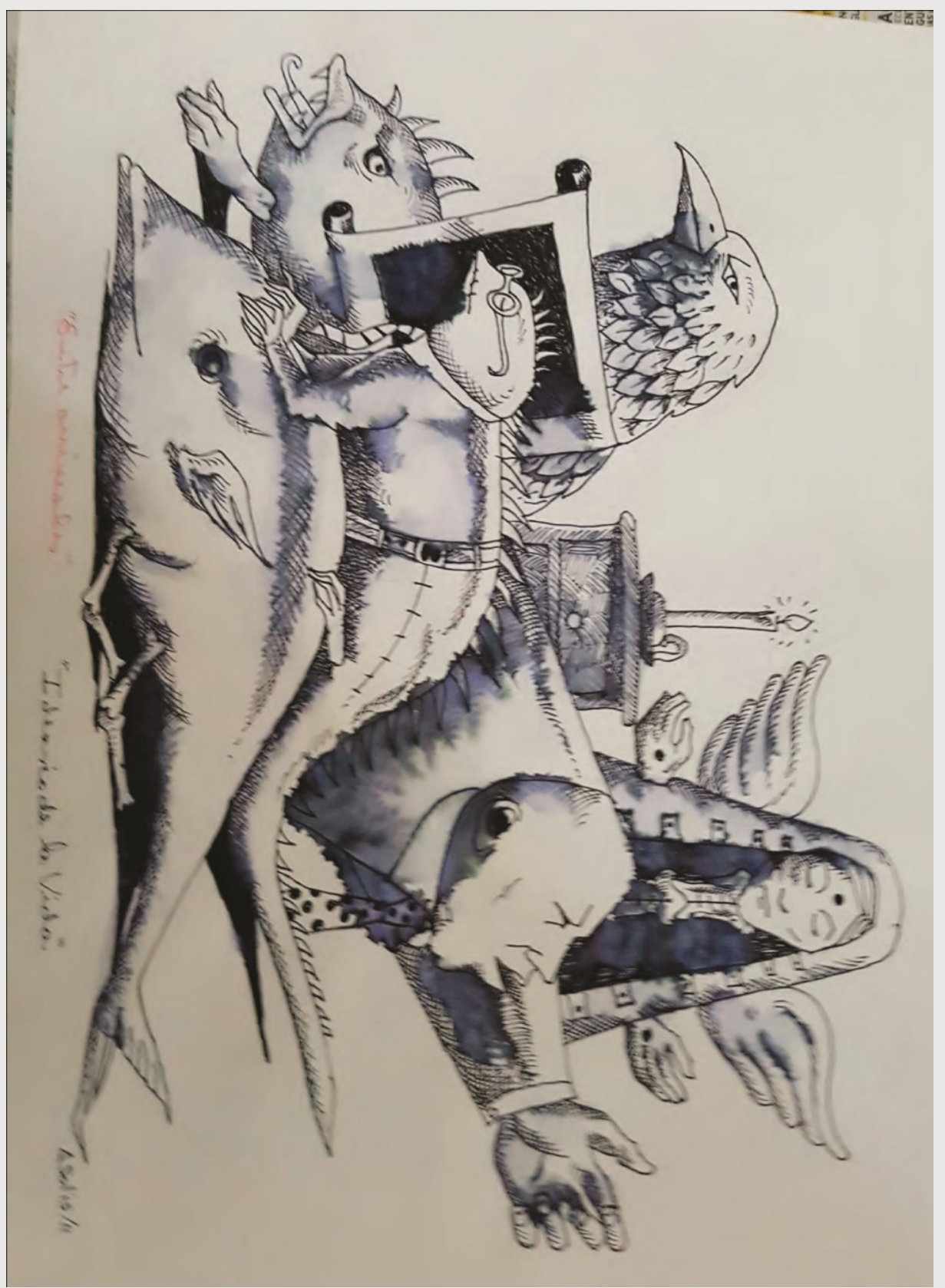

Armando Solis 